\title{
Hardness Tests and Dimensional and Shape Precision Analysis of Construction and Agricul- tural Machinery Components
}

\author{
Petra Kvasnová1, Martin Kučerka ${ }^{1}$, Dušan Hrubý², Daniel Novák ${ }^{1}$, Viktor Novák ${ }^{3}$ \\ ${ }^{1}$ Matej Bel University, Faculty of Natural Sciences, Department of Mathematics, Tajovského 40, 97401 Banská Bystrica, \\ Slovakia. E-mail: petra.kvasnova@umb.sk, martin.kucerka@umb.sk, daniel.novak@umb.sk \\ ${ }^{2}$ Slovak University of Agriculture in Ntra, Faculty of Engineering, Department of Electrical Engineering, Automation \\ and Informatics, Tr. Andreja Hlinku 2, SK949 76 Nitra, Slovakia, dusan.hruby@uniag.sk \\ ${ }^{3}$ Czech University of Life Sciences Prague, Faculty of Engineering, Department of Electrical Engineering and Automa- \\ tion, Kamýcká 129, 16521 Prague 6, Czech Republic. E-mail: novakviktor@tf.czu.cz
}

\begin{abstract}
The article deals with hardness tests and dimensional and shape precision analysis of construction and agricultural machinery components, namely with the clamping head and case of hydraulic hammer. The clamping head is made of 414220 class $(1.7131,16 \mathrm{MnCr5})$ construction stainless steel and the case is made of 415130 class $(1.7218$, 25CrMo4) construction stainless steel. The micro hardness was measured on VICKERS LM 700 AT hardness tester, according to the national standard STN EN ISO 6507-1: this procedure includes injection of a diamond regular four-bladed pyramid with a $136^{\circ}$ peak angle into the tested material with following parameters: objective lens X50, load $10 \mathrm{~N}$, indentation time $10 \mathrm{~s}$. The average $\mathrm{HV}$ micro hardness value was determined from $10 \mathrm{measu}-$ ring points (distances) on 70 samples of the hydraulic hammer case and from 10 measuring points (distances) on 200 samples of the hydraulic hammer clamping head. To measure dimensional and shape accuracy, Perthometer MAHR, equipped with PCV 350 slider unit with sensors with $350 \mathrm{~mm}$ length range and a mobile 6-axis 3D measuring arm Romer Absolute Arm 7535 with a working range of 3.5 m were used. This way, basic contour elements were determined: radii, distances and angles. Using the mobile 3D measuring arm, the tolerances of circularity, coaxiallity and perpendicularity were also measured. Technical drawings, contourrograph measuring protocols and tables of dimensional and shape precision deviations are listed in the conclusion of the article.
\end{abstract}

Keywords: Hardness tests, dimensional and shape precision analysis, construction stainless steel, production engineering, construction and agricultural machines

\section{Introduction}

At present, all companies have been established and should maintain an Integrated Management System (IMS). This way, the management and thus the production and service are committed to meet the requirements of the Quality Management System (STN EN ISO 9001) and the Environmental Management System (STN EN ISO 14001). The permanent goal is to increase the efficiency by optimization of the entire production process.

Product quality is a dominant factor that affects the development and success of production. To ensure a high level of product quality check, it is necessary to build an air-conditioned check center as well as quality check zones directly within the production itself, equipped with state-of-the-art measuring devices.

\section{Materials and methodes}

Construction and agricultural machinery consist of components that have to meet the tolerances of dimensional and shape accuracy as well as the hardness of the materials themselves. Based on the above, there were been performed hardness measurements on components of heavy machinery, namely on the clamping head and case of Montabert hydraulic hammer, currently a fairly young mark on the market. Manufacturers especially pay attention to high performance, taking into account the requirements for noise emissions and reduction of vibration transmitted to the operator $[2,5,6]$. The clamping head of the hydraulic hammer is made of Stainless Steel Class $414220(1.7131,16 \mathrm{MnCr} 5)$ the case is made of Stainless Steel Class $415130(1.7218,25 \mathrm{CrMo} 4)$ stainless steel case $[1,3,7]$.

To verify the required quality of the products, following measuring devices were used: hardness was measured using the LM 700 AT Vickers Micro Hardness Tester, dimensional and shape accuracy was determined using contourrograph Perthometer MAHR (Fig. 3) and mobile 6axis 3D measuring arm Romer Absolute Arm 7535 (Fig. 4) and the roughness was measured by Mitutoyo SJ-301 roughness meter.

Chemical composition of respective steels according to norm EN 10084-94 is stated in Tab. 1.

Tab. 1 Chemical composition in wt. \% of used construction stainless steels according to STN EN 10083

\begin{tabular}{|l|l|l|l|l|l|l|l|l|l|l|}
\hline & $\mathrm{C}$ & $\mathrm{Si}_{\max }$ & $\mathrm{Mn}$ & $\mathrm{P}_{\max .}$ & $\mathrm{S}_{\max }$ & $\mathrm{Cr}$ & $\mathrm{Mo}$ & $\mathrm{Ni}$ & $\mathrm{Cu}$ & $\mathrm{Al}$ \\
\hline Steel 414220 & 0.13 & 0.23 & 1.25 & 0.010 & 0.020 & 1.02 & - & 0.05 & 0.22 & 0.02 \\
\hline Steel 415130 & $0.20 \div 0.31$ & 0.43 & $0.56 \div 0.94$ & 0.030 & 0.040 & $0.85 \div 1.25$ & $0.12 \div 0.33$ & - & - & - \\
\hline
\end{tabular}

Hardness measurements were performed on the LM 700 AT Vickers Micro Hardness Tester (Fig. 2) using an
X50 lens with a $10 \mathrm{~N}$ load for time 10 seconds. The Vickers hardness test is carried out according to the national 
standard STN EN ISO 6507-1, which consists in the injection of a diamond regular four-bladed pyramid with a peak angle of $136^{\circ}$ into the test material. The loading force acts in a perpendicular direction on the surface of the test body. The Vickers Hardness is referred as HV and it is defined as the ratio of the load force $F$ to the surface $\mathrm{S}$ of the imprint [4]. The principle of the Vickers Hardness Test, including the geometric data for calculating the surface of the imprint $\mathrm{S}$, is shown in Fig. 1, the hardness is determined according to formula (1).

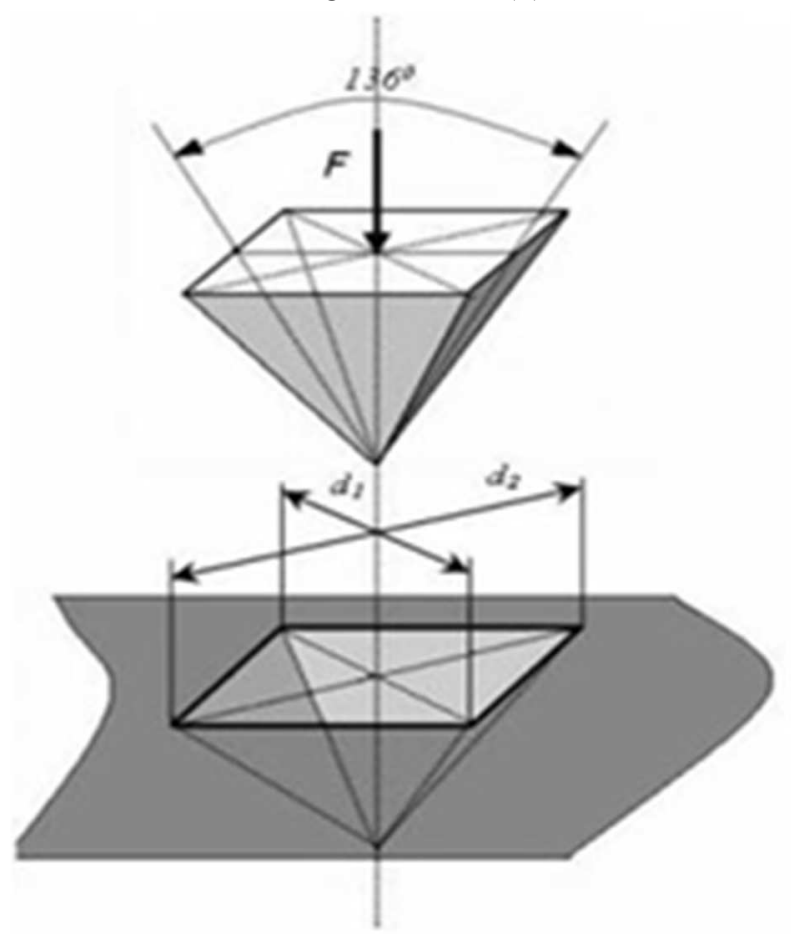

Fig. 1 Principle of Vickers Hardness measuring

$$
\begin{gathered}
H V=K \cdot \frac{F}{S}=0.102 \cdot \frac{2 F \sin \frac{136}{2}}{d^{2}} \\
K=\frac{1}{g}=\frac{1}{9.81}=0.102
\end{gathered}
$$

Where:

K...constant,

$\mathrm{g}_{\mathrm{n}}$... acceleration due to gravity,

F...loading force,

S...indentation surface,

$\mathrm{d}$... aritmetical average of diagonals $\mathrm{d} 1$ and $\mathrm{d} 2$

The actual manufactured surfaces of the components may differ from the ideal (theoretical) surfaces by their dimensions and shape, i.e. they are not made with absolute precision. Therefore, it is necessary to prescribe the permissible dimensional and shape inaccuracy. The requirement to keep the deviation limits (permissible inaccuracies) relates primarily to functional surfaces that encounter other surfaces and that ensure the proper functioning of the whole device. For this reasons, the dimensional and shape accuracy check was performed on the clamping head and on the hydraulic hammer case.

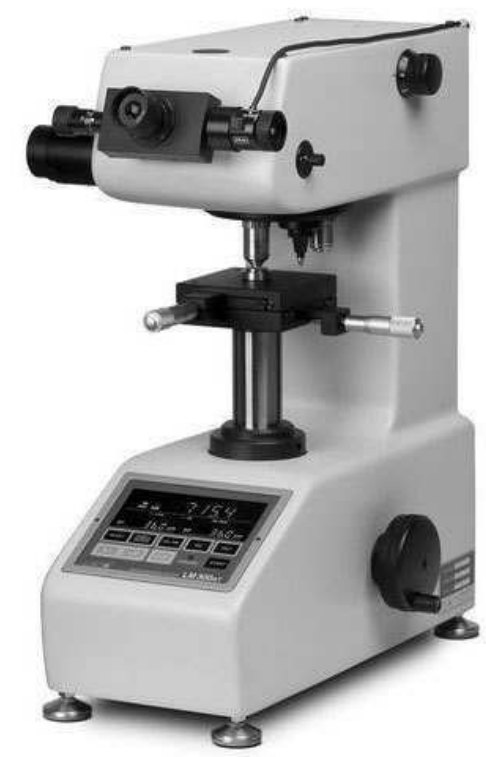

Fig. 2 LM 700 AT Vickers Micro Hardness Tester

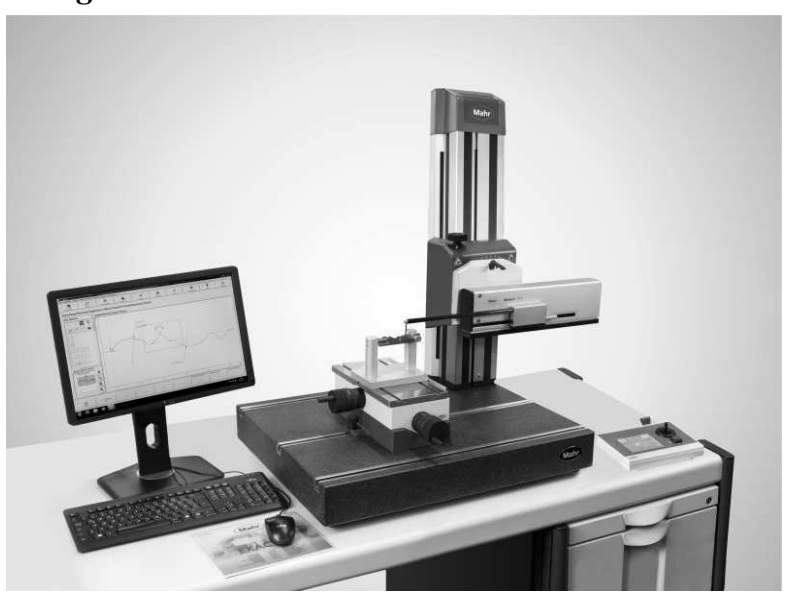

Fig. 3 Contourrograph Perthometer MAHR

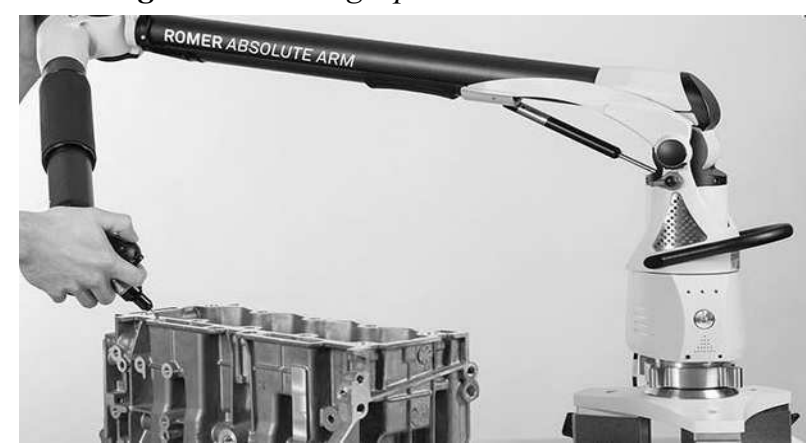

Fig. 4 6-axis 3D measuring arm Romer Absolute Arm 7535

Measurements using the contourrograph Perthometer MAHR were performed using a PCV 350 slider with sensors, that can measure up to $350 \mathrm{~mm}$ in length. It was possible to measure precisely and simply the contour elements: radii, distances and angles. The measuring arm Romer Absolute Arm 7535 was used to determine the tolerances of circularity, coaxiallity and perpendicularity. The hardness was evaluated using the Mitutoyo SJ-301 roughness meter, using a quantitative contact measuring method according to norm STN EN ISO 3274, which is 
based on the small diameter of the point tip that is a part of the sensor. Hereby the transverse roughness was measured, i.e. the roughness perpendicular to the machining tracks.

\section{Results and discussion}

Vickers hardness tests were performed on the hammer clamping head made of stainless steel 414220 , using the LM 700 AT Vickers Micro Hardness Tester. The tests were performed on 200 randomly selected pieces using the load of $10 \mathrm{~N}$ and indentation time of 10 seconds. The test was performed with 10 injections from the surface of the material to its core. The course of measured average hardness values is stated in Table 2 as well as it is presented graphically in Graph 1. The distance from the surface to the limit hardness border (Eht 580 HV 1) is derived from Graph 1.

Tab. 2 Hardness of the clamping head material

\begin{tabular}{|l|l|l|}
\hline Point & Distance [mm] & Hardness [HV1] \\
\hline 1. & 0.1 & 799 \\
\hline 2. & 0.2 & 703 \\
\hline 3. & 0.3 & 686 \\
\hline 4. & 0.4 & 625 \\
\hline 5. & 0.5 & 550 \\
\hline 6. & 0.7 & 549 \\
\hline 7. & 0.9 & 543 \\
\hline 8. & 1.0 & 536 \\
\hline 9. & 1.1 & 514 \\
\hline 10. & 1.2 & 500 \\
\hline
\end{tabular}

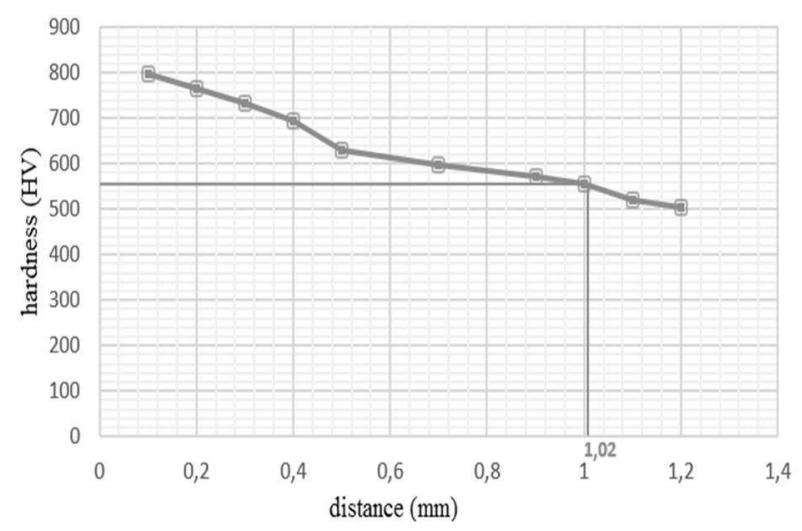

Graph 1 Course of hardness of the clamping head material

Tab. 3 Hardness of the hydraulic hammer case

\begin{tabular}{|l|l|l|}
\hline Point & Distance [mm] & Hardness[HV1] \\
\hline 1. & 0.1 & 846 \\
\hline 2. & 0.2 & 762 \\
\hline 3. & 0.3 & 686 \\
\hline 4. & 0.5 & 613 \\
\hline 5. & 0.7 & 580 \\
\hline 6. & 0.9 & 577 \\
\hline 7. & 1.0 & 572 \\
\hline 8. & 1.1 & 568 \\
\hline 9. & 1.2 & 551 \\
\hline 10. & 1.4 & 544 \\
\hline
\end{tabular}

The hardness on the hammer case from stainless steel 415130 was measured using the same method. The tests were carried out on 70 randomly selected pieces using the same test parameters; the force acted in the perpendicular direction to the surface of the test body at 10 points. The measured average hardness values of the case material are shown in Table 3, the hardness course is also depicted graphically in Graph 2.

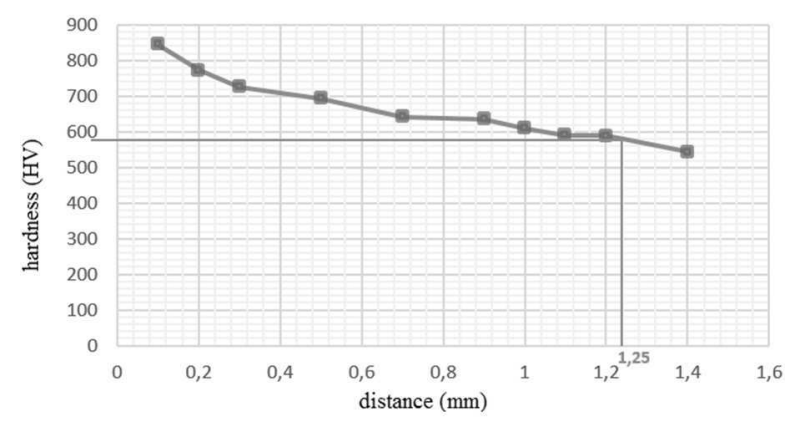

Graph 2 Course of hardness of the hammer case material

By means of a series of injections from the surface of the material up to its core was inquired the hardness of the respective layer of the clamping head and of the hydraulic hammer case. The course of hardness values is shown on the graphs and the distance from the surface to the limit hardness border EHT is also calculated, whereby it is true:

quenching depth $=$ distance from surface to limit hardness EHT

For the clamping head, the limit hardness $550 \mathrm{HV} 1$ was determined using the DIN 50190 / ISO 2639 Carburizing standards. Reading from Graph 1, the quenching depth CHD is equal to $1.02 \mathrm{~mm}$, thus the limit hardness for structural steel case 414220 is at the depth of 1.02 $\mathrm{mm}$.

For the structural steel 415130 case, the limit hardness $580 \mathrm{HV} 1$ was determined. Reading from Graph 2, the quenching depth CHD is $1.25 \mathrm{~mm}$, i.e. the limit hardness for the 415130 steel case lays at the depth of 1.25 $\mathrm{mm}$.

Besides the hardness of the component and hereby its suitability for its purpose, it is also necessary to check the roughness and its dimensional and shape accuracy, since actual manufactured surfaces differ from the ideal (theoretical) surfaces by their dimensions, shape and position. The dimensions of individual parts must fulfill the requirements of correct connection and mutual contact and also meet the prescribed function and interchangeability requirements. Since the chosen parts (clamping head and hydraulic hammer case) are parts with prescribed precision and tolerance limits, their dimensions were checked and, in the case of out of keeping with STN ISO 129-1 (length and angular accuracy) and with STN EN ISO 1101: 2017-08 (geometrical tolerance) it was necessary draw the consequences and repair or replace the affected components to the desired accuracy. 


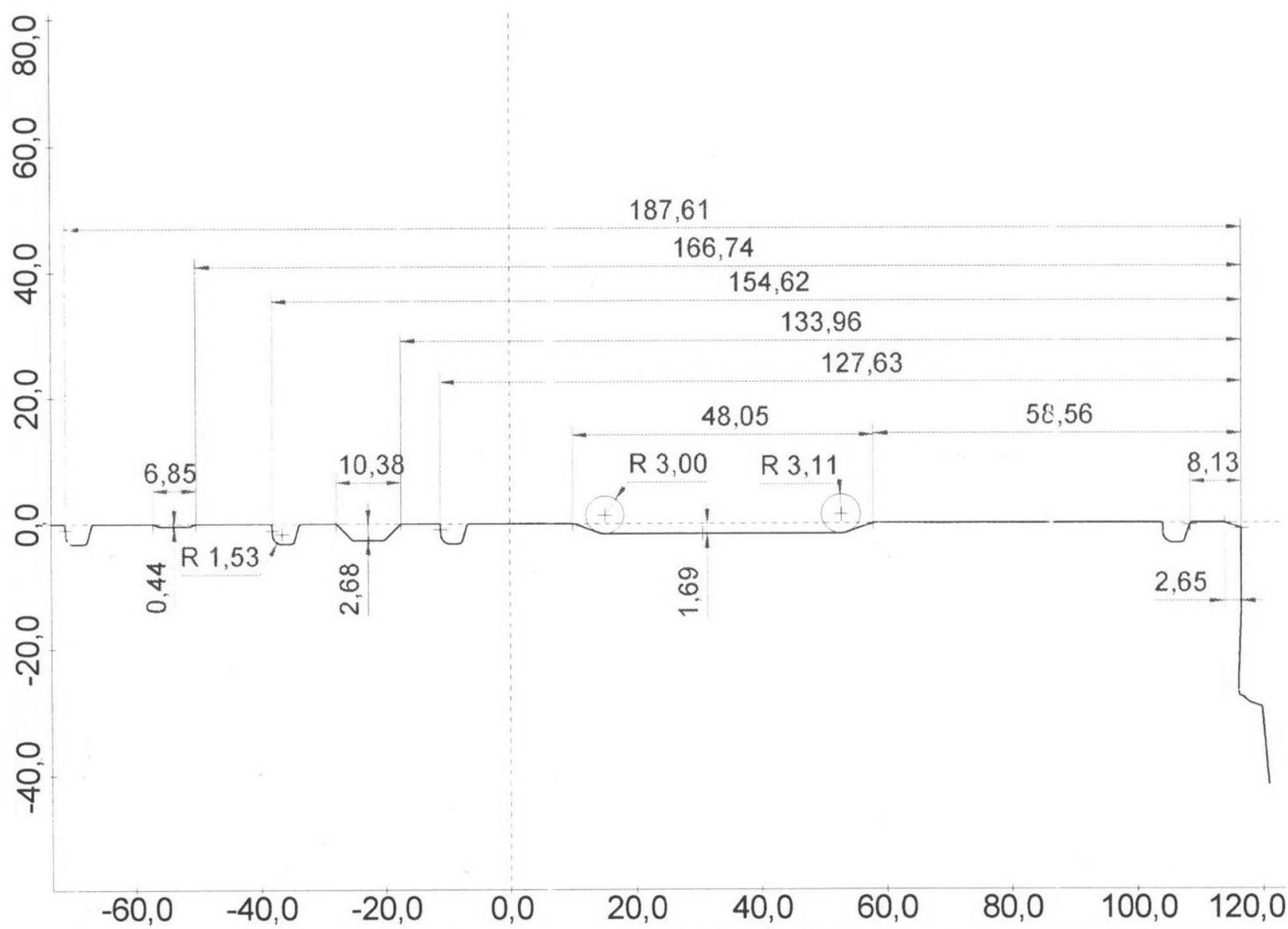

Fig. 5 Conturrograph measuring protocol

Tab. 4 Measurements of circularity, coaxiallity and perpendicularity on hydraulic hammer case

\begin{tabular}{|c|c|c|c|c|c|c|}
\hline $\mathrm{AX}$ & NOMINAL & $+\mathrm{TOL}$ & - TOL & MEAS & $\mathrm{DEV}$ & OUTTOL \\
\hline MM & \multicolumn{6}{|c|}{ DIM LOC1 = LOCATION OF CIRCLE CIR-A-1 } \\
\hline $\mathrm{D}$ & 84.9925 & 0.0075 & -0.0075 & 84.9928 & 0.0003 & 0.0000 بسبس \\
\hline $\mathrm{MM}$ & \multicolumn{6}{|c|}{ DIM RND1 = ROUNDNESS OF CIRCLE CIR-A-1 } \\
\hline $\mathrm{M}$ & 0.0000 & 0.0050 & 0.0000 & 0.0054 & 0.0054 & 0.0004 0.س \\
\hline $\mathrm{MM}$ & \multicolumn{6}{|c|}{ DIM LOC2 = LOCATION OF CIRCLE CIR-A-2 } \\
\hline $\mathrm{M}$ & 84.9925 & 0.0075 & -0.0075 & 84.9936 & 0.0011 & 0.0000 لصبنس \\
\hline MM & \multicolumn{6}{|c|}{ DIM RND2 = ROUNDNESS OF CIRCLE CIR-A-2 } \\
\hline $\mathrm{M}$ & 0.0000 & 0.0050 & 0.0000 & & 0.0033 & 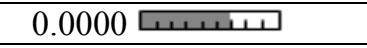 \\
\hline $\mathrm{MM}$ & \multicolumn{6}{|c|}{ DIM LOC3 = LOCATION OF CIRCLE CIR-B } \\
\hline $\mathrm{D}$ & 0.0033 & 0.0075 & -0.0075 & 86.9908 & -0.0017 & 0.0000 पाया \\
\hline $\mathrm{MM}$ & \multicolumn{6}{|c|}{ DIM RND3 = ROUNDNESS OF CIRCLE CIR-B } \\
\hline $\mathrm{M}$ & 0.0000 & 0.0050 & 0.0000 & 0.0030 & 0.0030 & |سسس \\
\hline $\mathrm{MM}$ & \multicolumn{6}{|c|}{ DIM LOC4 = LOCATION OF CIRCLE CIR-VN } \\
\hline $\mathrm{D}$ & 69.0000 & 0.0095 & -0.0095 & 69.0099 & 0.0099 & 0.0004 0.س \\
\hline MM & \multicolumn{6}{|c|}{ DIM RND4 = ROUNDNESS OF CIRCLE CIR-VN } \\
\hline $\mathrm{M}$ & 0.0000 & 0.0050 & 0.0000 & 0.0046 & 0.0046 & 0.0000 0س \\
\hline $\mathrm{AX}$ & NOMINAL & $+\mathrm{TOL}$ & - TOL & MEAS & DEV & OUTTOL \\
\hline $\mathrm{MM}$ & \multicolumn{6}{|c|}{ DIM CONCEN1 = CONCENTRICITY FROM CIRCLE CIR-B TO CIRCLE CIR-A-2 } \\
\hline M & 0.0000 & 0.0050 & 0.0000 & 0.0015 & 0.0015 & 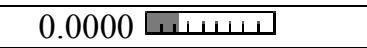 \\
\hline $\mathrm{MM}$ & \multicolumn{6}{|c|}{ DIM CONCEN2 = CONCENTRICITY FROM CIRCLE CIR-VN TO CIRCLE CIR-A-2 } \\
\hline M & 0.0000 & 0.0050 & 0.0000 & 0.0034 & 0.0034 & 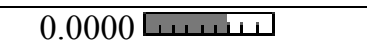 \\
\hline $\mathrm{AX}$ & NOMINAL & $+\mathrm{TOL}$ & - TOL & MEAS & $\mathrm{DEV}$ & OUTTOL \\
\hline$\perp \mathrm{MM}$ & \multicolumn{6}{|c|}{ DIM PERP1 = PERPEND OF PLANE PLN1, RFS TO LINE LIN1, RFS EXTEND=0.0000 } \\
\hline $\mathrm{M}$ & 0.0000 & 0.0100 & 0.0000 & 0.0035 & 0.0035 & 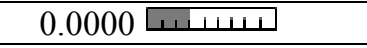 \\
\hline$\perp \mathrm{MM}$ & \multicolumn{6}{|c|}{ DIM PERP2 = PERPEND OF PLANE PLN1, RFS TO LINE LIN1, RFS EXTEND=0.0000 } \\
\hline $\mathrm{M}$ & 0.0000 & 0.0100 & 0.0000 & 0.0024 & 0.0024 & 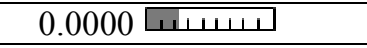 \\
\hline
\end{tabular}


Measurements were carried out using the contourrograph Perthometer MAHR and mobile 6-axis 3D measuring arm Romer Absolute Arm 7535 with a working range of $3.5 \mathrm{~m}$. The contourrograph Perthometer MAHR was equipped PCV 350 slider with sensors with measuring range length of $350 \mathrm{~mm}$, this way it was possible to measure precisely and simply the contour elements: radii, distances and angles.

According to norm STN EN ISO 1101: 2017-08, the tolerances of circularity, coaxiallity and perpendicularity were measured at both components. The measurement Conturograph protocol from the Montabert Hydraulic Hammer case is shown in Figure 5. The tolerances of circularity, coaxiallity and perpendicularity are stated in Table 4 .

Based on these measurements, it was found that not all dimensions lay within the tolerance set by the standard. This was mainly about the CIR-A-1 circularity, where the dimension of $84.9925 \mathrm{~mm}$ was prescribed, with a nominal value of $0.0000 \mathrm{~mm}$ and a possible tolerance of $\pm 0.0050 \mathrm{~mm}$. By the measurement, a circularity with a nominal value of 0.0054 was measured, which exceeds the tolerance by $0.0004 \mathrm{~mm}$; this measurement from the $3 \mathrm{D}$ measuring arm was evaluated as critical.

For this reason, the components had to be surface-finished to meet strict tolerances of circularity, coaxiallity and perpendicularity. After this operation, the parts were re-measured and the contourrograph results are shown in Figure 6 and the tolerances of circularity, coaxiallity and perpendicularity are summarized in Table 5.

New measurements on surface-finished parts proved that the inspected dimensions lay within the tolerance limits, thus the components are evaluated as suitable for inclusion into the manufacturing process and they are usable in practice.

Together with the previous measurements was determined the roughness of the surface of the hydraulic hammer case. The roughness is according to STN EN ISO 4287: 1999-12 defined as a sum of the unevenness of the surface with relatively small distances, arising as a result of the used production technology. The portable Mitutoyo SJ-301 roughness meter was used, the roughness was measured in the perpendicular direction to the machining tracks. The topic of roughness measuring of other alloys is nearly described in [8].

The roughness according to the first measurement was determined $\mathrm{Ra}=0.22$; after re-machining of the surface due to the named non-fulfilment of the prescribed circularity tolerances, the new roughness value $\mathrm{Ra}=0.17$ was measured. Both measured roughness values meet the required surface quality from the customer.

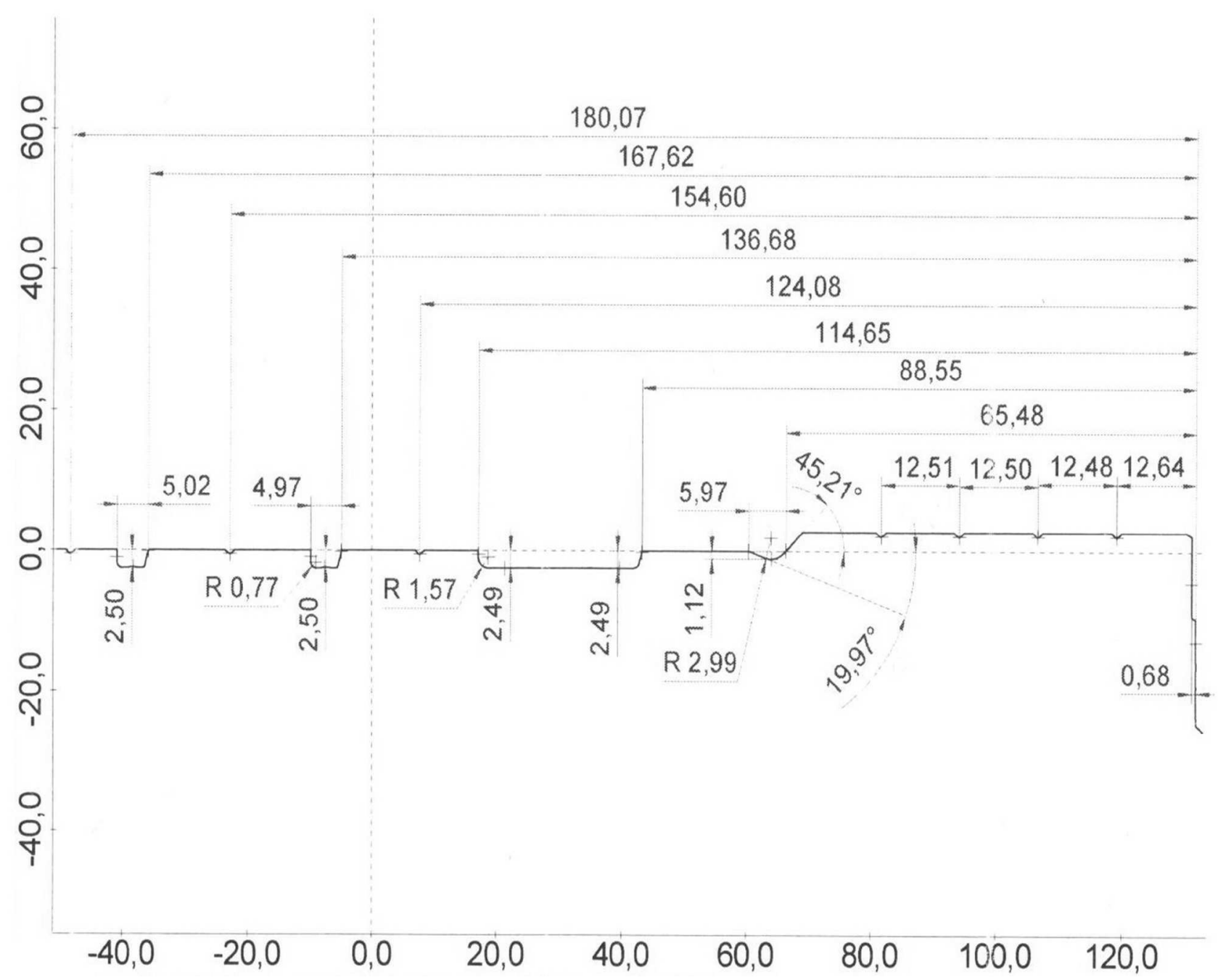

Fig. 6 Conturrograph measuring protocol (after re-maschining) 
Tab. 5 Measurements of circularity, coaxiallity and perpendicularity on hydraulic hammer case (after re-maschining)

\begin{tabular}{|c|c|c|c|c|c|c|}
\hline $\mathrm{AX}$ & NOMINAL & $+\mathrm{TOL}$ & - TOL & MEAS & DEV & OUTTOL \\
\hline 田 $\mathrm{MM}$ & \multicolumn{6}{|c|}{ DIM LOC1 = LOCATION OF CIRCLE CIR-A-1 } \\
\hline $\mathrm{D}$ & 84.9925 & 0.0075 & -0.0075 & 84.9986 & -0.0039 & |سسست 0000 0.000 \\
\hline O MM & \multicolumn{6}{|c|}{ DIM RND1 = ROUNDNESS OF CIRCLE CIR-A-1 } \\
\hline $\mathrm{M}$ & 0.0000 & 0.0050 & 0.0000 & 0.0034 & 0.0034 & 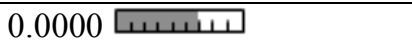 \\
\hline 田 & \multicolumn{6}{|c|}{ DIM LOC2 = LOCATION OF CIRCLE CIR-A-2 } \\
\hline $\mathrm{M}$ & 84.9925 & 0.0075 & -0.0075 & 84.8990 & -0.0035 & טسستس 0000 0.000 \\
\hline $\mathrm{O} \mathrm{MM}$ & \multicolumn{6}{|c|}{ DIM RND2 = ROUNDNESS OF CIRCLE CIR-A-2 } \\
\hline $\mathrm{M}$ & 0.0000 & 0.0050 & 0.0000 & 0.0018 & 0.0018 & 0.0000 |سسس \\
\hline 田 MM & \multicolumn{6}{|c|}{ DIM LOC3 = LOCATION OF CIRCLE CIR-B } \\
\hline $\mathrm{D}$ & 86.9925 & 0.0075 & -0.0075 & 86.9983 & -0.0042 & سسست 0000 0000 \\
\hline O MM & \multicolumn{6}{|c|}{ DIM RND3 $=$ ROUNDNESS OF CIRCLE CIR-B } \\
\hline $\mathrm{M}$ & 0.0000 & 0.0050 & 0.0000 & 0.0020 & 0.0020 & | 0سسس \\
\hline 田 MM & \multicolumn{6}{|c|}{ DIM LOC4 = LOCATION OF CIRCLE CIR-VN } \\
\hline $\mathrm{D}$ & 69.0000 & 0.0095 & -0.0095 & 68.9980 & -0.0020 & 0.0000 0سسس \\
\hline $\mathrm{O}$ MM & \multicolumn{6}{|c|}{ DIM RND4 = ROUNDNESS OF CIRCLE CIR-VN } \\
\hline $\mathrm{M}$ & 0.0000 & 0.0050 & 0.0000 & 0.0050 & 0.0050 & 0.0000 0.00س 0 000 \\
\hline $\mathrm{AX}$ & NOMINAL & $+\mathrm{TOL}$ & - TOL & MEAS & DEV & OUTTOL \\
\hline (?) MM & \multicolumn{6}{|c|}{ DIM CONCEN1 = CONCENTRICITY FROM CIRCLE CIR-B TO CIRCLE CIR-A-2 } \\
\hline $\mathrm{M}$ & 0.0000 & 0.0050 & 0.0000 & 0.0003 & 0.0003 & 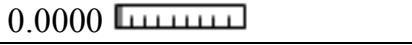 \\
\hline (2) $\mathrm{MM}$ & \multicolumn{6}{|c|}{ DIM CONCEN2 = CONCENTRICITY FROM CIRCLE CIR-VN TO CIRCLE CIR-A-2 } \\
\hline $\mathrm{M}$ & 0.0000 & 0.0050 & 0.0000 & 0.0009 & 0.0009 & سسسس 0.0000 \\
\hline $\mathrm{AX}$ & NOMINAL & $+\mathrm{TOL}$ & - TOL & MEAS & DEV & OUTTOL \\
\hline$\perp \mathrm{MM}$ & \multicolumn{6}{|c|}{ DIM PERP1 $=$ PERPEND OF PLANE PLN1, RFS TO LINE LIN1, RFS EXTEND $=0.0000$} \\
\hline $\mathrm{M}$ & 0.0000 & 0.0100 & 0.0000 & 0.0024 & 0.0024 & سسس 0.0000 \\
\hline$\perp \mathrm{MM}$ & \multicolumn{6}{|c|}{ DIM PERP2 $=$ PERPEND OF PLANE PLN1, RFS TO LINE LIN1, RFS EXTEND $=0.0000$} \\
\hline M & 0.0000 & 0.0100 & 0.0000 & 0.0043 & 0.0043 & 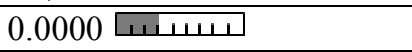 \\
\hline
\end{tabular}

\section{Conclusion}

Dimensional standards contain, for nominal sizes, data on permitted deviations in dimensions and shapes. If they are part of the order, they must be respected by the manufactures and they become part of the technical delivery terms. The compliance with dimensions and shapes prescribed in dimensional standards is a part of the product's quality requirements; thus the dimension checking is a subject to quality check.

As our measurements have found, not all dimensions on the Montabert hydraulic hammer case are within the tolerances set by the standard. This was mainly the CIRA-1 circularity, where the dimension $84.9925 \mathrm{~mm}$ with a nominal value of $0.0000 \mathrm{~mm}$ was prescribed, with a possible tolerance of $\pm 0.0050 \mathrm{~mm}$. By real measurement, circularity with a nominal value of 0.0054 was measured, which exceeds the tolerance by $0.0004 \mathrm{~mm}$, thus this measurement from the 3D measuring arm was evaluated as critical. After additional surface-finishing, the dimensions and shape of the component have improved, the aforementioned circularity CIR A-1 then reached the desired value of $0.0000 \mathrm{~mm}$.

The dimensions of the other parts of the hydraulic hammer case have been also improved after re-machining. E.g. the CIR A-2 circularity from $0.0033 \mathrm{~mm}$ to $0.0018 \mathrm{~mm}$, CIR B circularity has improved from 0.0030 $\mathrm{mm}$ to $0.0020 \mathrm{~mm}$; however, these dimensions have met the deviation requirements even before the re-machining.
Similarly, the coaxiallity parameters of the components have also improved, e.g. the coaxiallity CIR-B to CIR A2 from $0.0015 \mathrm{~mm}$ to $0.0003 \mathrm{~mm}$, coaxiallity CIR-VN to CIR A-2 from original $0.0034 \mathrm{~mm}$ to $0.0009 \mathrm{~mm}$.

When measuring the roughness, the quality of the measured surface increased from the original $\mathrm{Ra}=0.22$ to $\mathrm{Ra}=0.17$. Although the old and new measured roughness value met the quality requirements on surface layers from the customer, the component did not pass through the control due the unsatisfactory circularity value before the re-machining. Therefore, the additional surface-finishing increased the accuracy of circularity to the desired level and at the same time it also reduced the roughness of the material.

Improvements in production methods and machines, as well as tightening final product shape requirements, results in reducing the deviations from the nominal dimensions and from the ideal shape of the product. However, advance in production engineering is often ahead of current normative state. Therefore, manufacturers who are equipped with more advanced technology are able to produce more precisely than the standard requires.

\section{Acknowledgement}

This paper has been supported by KEGA 019UMB4/2018: Diversification and Strengthening of Undergraduate Training of Future Teachers with an Emphasis on Technical Education. 


\section{References}

[1] CALIK, A., UCAR, N., KOCASLAN, A., KARAKAS, S. (2017). Effect of interrupted boriding on microstructure and mechanical properties of $16 \mathrm{MnCr} 5$ steels. In: Surface Review and Letters. ISSN 0218625X.

[2] DADO, M., SCHWARZ, M., OČKAJOVÁ, A., HNILICA, R., BOROŠOVÁ, D. (2016). Efficiency of local exhaust ventilation system during stainless steel grinding. In: Manufacturing Technology, Vol. 16, No. 1, pp. 49-53. J. E. Purkyne University in Ústí nad Labem, Ústí nad Labem, Czech Republic. ISSN 1213-2489.

[3] CHAN, Y.L., XU, X. (2017). Evaluation and comparison of lubrication methods in finish machining of hardened steel mould inserts. In: Proceedings of the Institution of Mechanical Engineers, Part B: Journal of Engineering Manufacture, Vol. 231, Issue 14 , pp. 2458-2467.

[4] JENSON, A.D., ROY, S., SUNDARARAJAN, S. (2018) The evolution of hardness and tribofilm growth during running-in of case carburized steel under boundary lubrication. In: Tribology International, vol. 118, pp. 1-10.
[5] JONŠTA, P., VLČKOVÁ, I., KRIŠŤÁK, L., ŠPIČKA, I., JONŠTA, Z. (2015). Contribution to the thermal properties of selected steels. In: Metalurgija, Vol. 54 No. 1 Siječanj, s. 187-190. ISSN 0543-5846.

[6] OČKAJOVÁ, A., STEBILA, J., RYBAKOWSKI, M., ROGOZINSKI, T., KRIŠŤÁK, L., LUPTÁKOVÁ, J. (2014). The granularity of dust particles when sanding wood and wood-based materials. In: Advanced Materials Research. Vol. 1001, pp. 432-437. DOI: 10.4028/www.scientific.net/ AMR.1001. 432.

[7] SUYAMA, D.I., DINIZ, A.E., PEDERIVA, R. (2016). The use of carbide and particle-damped bars to increase tool overhang in the internal turning of hardened steel. In: International Journal of Advanced Manufacturing Technology, 86(5-8), pp. 2083-2092.

[8] LATTNER, R., HOLEŠOVSKÝ, F., NOVÁK, M. VRABEL, M. (2016). Grinding of Titanium Alloy Ti6A14V with Silicon Carbide Grinding Wheel. In: Manufacturing Technology, Vol. 16, No. 1, pp. 159-162. J. E. Purkyne University in Ústí nad Labem, Ústí nad Labem, Czech Republic. ISSN 1213-2489. 